\title{
DESAPROPRIAÇÃO DAS MEMÓRIAS INDESEJÁVEIS: OPRESSÃO E RESISTÊNCIA NO CENTRO HISTÓRICO DE SALVADOR
}

\author{
Juliana Neves Barros \\ Bacharela em direito pela Universidade Federal da Bahia, assessora jurídica da \\ Associação dos Advogados dos Trabalhadores Rurais
}

\section{Vanessa Souza Pugliese}

Bacharela em direito pela Universidade Federal da Bahia, assessora jurídica da Associação Vida Brasil

RESUMO: Pretendemos analisar aqui a opção administrativa pela desapropriação na restauração do Centro de Histórico de Salvador como forma de violação expressa do patrimônio cultural imaterial ali erigido, na medida em que possibilitou ao Governo a expulsão e o desenraizamento dos seus moradores - sobretudo da população negra que deu identidade ao espaço - e o exercício de uma soberania estatal voltada para um dirigismo totalizante das novas formas de ocupação do território. Frente a esse grosseiro projeto de reforma do maior conjunto arquitetônico da América Latina, tido como uma das intervenções "mais autoritárias, mais elitistas, mais centralizadas e mais segregadoras", que expulsou 95\% da população original, apontaremos focos de resistência que vêm lutando pela permanência no Pelourinho e provocando novos posicionamentos institucionais sobre a concepção de "patrimônio imaterial". Dentre esses, um destaque especial para a luta emblemática e vitoriosa dos ocupantes do "Prédio dos Alfaiates".

PALAVRAS-CHAVE: Desapropriação. Interesse público. Patrimônio Cultural. Políticas Patrimoniais. Centros Históricos. Identidade. Território. 


\section{A PROPRIEDADE E AS POLÍTICAS DE PROTEÇÃO DO PATRIMÔNIO HISTÓRICO}

A intervenção do Estado na propriedade privada tem por fundamento central a soberania estatal sobre os bens públicos e privados, de modo que o uso, o gozo e a fruição da propriedade individual possam estar sempre pautadas pelo atendimento ao interesse geral e ao bem estar coletivo. É a função social colocada como garantia fundamental no artigo $5^{\circ}, \mathrm{XXIII}$, da Constituição Federal, à qual deve adequar-se 0 exercício do direito individual garantido no inciso XXII do mesmo artigo.

Nesse sentido, entre os instrumentos colocados à disposição do Estado para intervir na propriedade privada, encontram-se a limitação administrativa, a ocupação temporária, a requisição, a servidão administrativa, o tombamento e a desapropriação, interessando-nos aqui a análise destes usos nas políticas de proteção e preservação dos patrimônios histórico- arquitetônicos.

É comum que a intervenção do Estado sobre os imóveis situados nos centros históricos, por serem em sua maioria dotados de riqueza arquitetônica, histórica e artística, seja orientada pelo ato de tombamento. Através deste, o bem adquire a condição de patrimônio cultural para efeito de conservação e preservação, sem sair da esfera particular, mas impondo ao proprietário limitações no direito de uso e fruição sobre o bem, subordinando-o a um regime especial que the implica vínculos de destinação, de modificabilidade e de relativa inalienabilidade, como orienta o Decreto-Lei no $25 / 37$.

É justamente por serem afetados de características públicas, de interesse da coletividade, que os bens tombados devem sofrer fiscalização e controle permanentes por parte do Estado, através do funcionamento de órgãos técnicos especializados, sempre buscando conciliar o direito individual de propriedade com o interesse coletivo. É o Estado na postura de orientador e incentivador da conduta individual no sentido do bem-estar social, devendo valorizar nas práticas patrimoniais, para além do aspecto físico-material dos imóveis, também o poder de simbolização impresso por aqueles que the ofereceram sentido orgânico. Integra-se aqui ao conceito de patrimônio histórico a idéia de patrimônio cultural, definido no artigo 216 da Constituição Federal como conjunto de bens, materiais e imateriais, 
referentes à identidade, à ação, à memória dos diferentes grupos formadores da sociedade brasileira, incluindo as formas de expressão e os modos de criar, fazer e viver.

Para Françoise Choay (2001), pela mundialização dos valores e das referências ocidentais, predominou por muito tempo nas políticas de recuperação dos sítios históricos uma síndrome narcisista do patrimônio, onde o aspecto imaterial e o valor antropológico não tinham lugar. Pellegrino reflete sobre a criação de patrimônios convenientes às estruturas de poder constituídas, às instituições em vias de consolidação e ao mercado que os reveste em investimento e bem de consumo cultural e turístico,

O que nos remete desde a origem da instituição patrimônio e seu uso pelo aparato do Estado para legitimar sua soberania sobre o território a partir da arregimentação de bens de alto valor simbólico até os dias atuais em que lugares são revitalizados, disputam para receberem o título de patrimônio mundial e são convertidos em vitrines para o flaneur contemporâneo deambular.

Reproduzida pelo Estado brasileiro, essa visão ocidentalizada levou à opção por medidas menos conciliatórias e mais drásticas na intervenção da propriedade sobre os bens tombados, imperando quase sempre na tomada dos imóveis pelo Estado, que, soberano, reorientou e reordenou a função dos sítios históricos única e exclusivamente para a ótica do turismo, beneficiando, sobretudo, aqueles dotados de potencial de consumo. Apartado de funções cotidianas, como moradia e trabalho, os sítios arquitetônicos perderam sua auto-sustentabilidade e se tornaram palco de investimentos maciços do Poder Público'.

A desapropriação sistemática foi o instituto escolhido para a "oficialização" do uso desses centros históricos. Pelo seu caráter unilateral, extremo, veremos como o uso desse instituto público foi falacioso no Centro Histórico de Salvador, onde o Estado invocou a propriedade sobre bens tombados para dar-Ihes uso privatístico e atender interesses da especulação imobiliária. Matou-se a esfera privada, particular, de grupos "indesejáveis", descartáveis por sua posição social, e institucionalizou-se ali a cultura folclorizada da "baianidade", recalcada com

\footnotetext{
1 Assim foi com o Pelourinho, em que as casas noturnas e as atrações culturais e artísticas são freqüentemente subsidiadas pelo Governo porque não conseguem se manter diante dos picos e repiques de um fluxo turístico em decadência, de olhar rapidamente esgotado frente a um espaço vazio de sentidos e de sua gente.
} 
pequenas amostras (baiana, capoeirista, trançadeira etc) dos modos de viver, fazer e criar de uma grande população negra expulsa do lugar.

\section{A INTERVENÇÃO NO CENTRO HISTÓRICO DE SALVADOR}

Maior conjunto arquitetônico da América Latina, o Centro Histórico de Salvador foi tombado como patrimônio histórico pelo IPHAN (Instituto do Patrimônio Histórico e Artístico Nacional) em 1984 e reconhecido pela Unesco como Patrimônio Cultural da Humanidade em 1985.

Em que pese a riqueza arquitetônica do sítio, por um bom tempo o Governo relegou a adoção de medidas de preservação na área. Desde a década de 1930, povoada por uma população de baixa renda, que ocupou o espaço deixado por elites que rumaram a novos bairros da cidade em crescimento, a área do Pelourinho passa a ser vista como um lugar decadente, associado à marginalidade, prostituição e pobreza. Torna-se, também, nesse percurso, núcleo simbólico de resistência da cultura negra:

A identidade alcançada pelo Pelourinho confunde-se com a história de resistência e afirmação da cultura negra em Salvador. Num momento de decadência do Centro face à expansão da cidade no sentido da Pituba e Iguatemi, foram os negros que ocuparam e deram vida ao Centro Histórico, retirando dele as mais variadas formas de sustento. Sintonizada com a tendência musical negra no mundo, e na onda de crescimento dos movimentos ligados aos direitos humanos, começou-se a desenvolver uma consciência local de resgate dos valores da negritude, tão oprimida ao longo da história do Brasil. A partir dessa época, os negros ganharam nova atitude em Salvador, incorporando ingredientes estéticos e políticos. O Pelourinho vira o centro desse fenômeno, a Jamaica era ali, o reggae, o cravinho (...) a tradicional Benção às terças-feiras viraram sensação (...) o Pelourinho passou a abrigar entre seus visitantes a classe média da cidade e turistas de todo o mundo (Rocha; 2002).

A presença marcante do Olodum e o crescimento da consciência negra transformaram o lugar e a própria cidade. Começou a fazer sentido, para todos, a incorporação do Pelô como novo centro de diversão.

Ainda em 1991, começam os trabalhos de intervenção do Governo Estadual na área do Centro Histórico. Antonio Carlos Magalhães e sua equipe, percebendo a força e a simbologia do que estava acontecendo, passam a canalizar investimentos 
na área e tirar proveito dessa pulsação. Através do Ipac (Instituto do Patrimônio Artístico Cultural), que atuava na área desde a década de 60, foi dado início a uma desestruturação dos laços comunitários em favor de uma suposta preservação dos monumentos históricos.

No auge do abandono, em 1992, toda a área foi inserida num grande projeto de reestruturação intitulado "Projeto de Reforma e Recuperação do Centro Histórico de Salvador" do Governo do Estado, cuja execução foi sumariamente instrumentalizada por meio de diversas desapropriações, fundamentadas sob o indeterminado conceito jurídico de "utilidade pública".

A mudança veio de cima: o Estado interveio no espaço público para transformá-lo em shopping. Processa-se aqui uma violenta intervenção política para colocar em prática uma pretensa recuperação do patrimônio histórico. O primeiro passo foi retirar a população que habitava os casarões coloniais para iniciar o processo de reforma dos prédios, a partir de 1991.

Nesse processo, cujos reflexos desastrosos em termos de preservação histórica e cultural apontaremos logo a seguir, foi flagrante a intervenção desarrazoada do Estado no seu exercício de discricionariedade administrativa. Observa-se no caso que, embora fosse necessária a reforma, dentre as alternativas possíveis para alcançar o fim público, optou-se pelo instituto mais radical de que se podia valer o Estado para intervir na propriedade privada. Através de sucessivos decretos desapropriatórios, o Poder Público passou a constranger os milhares de ocupantes a transferirem compulsoriamente ao Estado os imóveis declarados de utilidade pública.

A opção pela medida mais extrema, qual seja, a perda total e absoluta da propriedade pelo particular, revestiu-se de ato abusivo e totalmente descabido por dois flagrantes motivos. O primeiro refere-se ao fato de que a ocupação individual, grupal e familiar era perfeitamente compatível com o uso público do imóvel, o que deveria ter motivado o Poder Público a procurar preservar e reconhecer a propriedade dos ocupantes particulares, perseguindo o fim público pelos meios oferecidos através do tombamento. O segundo motivo é que, além de o exercício da propriedade individual não atentar contra o bem comum da coletividade, o fim público da preservação do patrimônio histórico e cultural no Pelourinho só seria contemplado de forma plena com a permanência daquelas pessoas em seus 
respectivos espaços. Afinal, representavam os verdadeiros edificadores da cultura local e eram elementos integrantes do patrimônio histórico imaterial.

A leitura atenta da pesquisa sócio-econômica e ambiental da Conder, apresentada anos depois para adequar-se às orientações de financiadores internacionais sobre a revitalização de áreas históricas, reconhece essa identidade da população local (CONDER, 2000):

Convém ressaltar que a área em questão manteve sua identidade como centro de referência cultural e de cidadania para grande parte da população da cidade - compartilhado por todas as classes e grupos sociais de Salvador. Essa identidade se estruturou com base no movimento cultural negro, firmado ao longo dos últimos anos, investindo o pelourinho de significados culturais que o divulgam nacional e internacionalmente. Há inclusive quem o considere o núcleo simbólico de identidade da cidade. Verifica-se sobretudo que o Pelourinho é um espaço onde as classes pobres adquirem representatividade, através de sua cultura, essencialmente a negra.

Note-se que, muitas dessas pessoas que aí vivem, desenvolvem trabalhos qualificados de baixa remuneração, como artesanato, pintores plásticos, vendedores de acarajé, sapateiros, músicos, mestres de capoeira, vidente, etc. O fato de terem escolhido este local degradado para viverem deve-se à centralidade da área, pois aí é o espaço cultural das populações de baixa renda.

Quando se eximiu de ações seguras, contínuas e eficientes sobre os imóveis da área tombada, praticamente desfuncionalizando seus órgãos técnicos de fiscalização, como o IPHAN e o IPAC, o Governo deixou explícito que o seu propósito para a área passava ao largo de qualquer contemplação dos direitos da população local sobre aquelas casas. Pelo contrário, interessava-Ihe a expulsão das famílias, o abortamento dos seus grupos culturais, dos personagens históricos e suas tradições, porque esses não engendravam a fileira daqueles dotados do potencial de consumo.

O Poder Público funcionou literalmente como um autêntico agenciador de interesses privados: retirou a propriedade de particulares que ocupavam há anos os prédios tombados, tomou para si a titularidade e, posteriormente, concedeu o uso dos imóveis do centro histórico a outros particulares para lhes dar destinação comercial. Às famílias, $\mathrm{R} \$ 700,1000,2000$ reais e a desconstrução de toda uma 
vida. Aos empresários, incentivos fiscais, anistias de dívidas e imóveis prontamente reformados.

Diante da dificuldade de acesso ao judiciário, tornou-se impossível questionar as ações de desapropriação. O Governo simplesmente negou-se a reconhecer a propriedade daqueles que há 20,30, 40 anos ocupavam os imóveis e só acionavam aqueles que constavam no cartório (em sua maioria desaparecidos, inexistentes etc). Os que chegaram a questionar judicialmente foram tratados como "estranhos ao processo", cuja petição deveria ser "desentranhada dos autos" (Dossiê dos Alfaiates, 2000). E assim, sem indenização ou relocação garantida, eram cumpridas as ordens liminares, com o apoio da força policial. Muitos valores depositados em juízo, sub-avaliados, acabaram voltando para os cofres do Estado. Nunca se reconheceu o pagamento de indenizações mesmo no discurso oficial. $O$ nome adotado sempre foi auxílio-relocação, cujo valor é ínfimo, discricionário e justificado como uma "preocupação social" do Governo com o destino das famílias, mas não como uma verba compensatória porque ninguém ali "tinha direito" sobre as casas ou era "proprietário".

Muitas famílias foram despejadas na surdina, à noite, às vésperas de Natal, Ano Novo, feriados, quando os espíritos de resistência não estavam tão em alerta. Logo após, as casas tinham suas janelas e portas rebocadas para os moradores não voltarem. Em muitos desses casos, observa-se que o patrimônio sequer foi restaurado e que o objetivo central mesmo era retirar dali os sujeitos "defeituosos" por sua pobreza. E o mais escancarado ainda se pode ver: antigo morador dormindo na calçada de sua antiga casa, ainda irretocada pelo Estado, criando mato pelas paredes. Com isso observamos ser esfarrapada a reiterada justificativa de muitos despejos por necessidade iminente de recuperação física dos prédios considerados "Patrimônio da Humanidade".

Pela desapropriação, o Governo colocou em curso seu ímpeto esteticista para o Pelourinho, desfigurando os velhos rostos e símbolos do Centro - pequenos comerciantes, sapateiros, prostitutas, músicos, capoeiristas, terreiros - para imprimir -lhe uma nova imagem: empresários, donos de joalherias, casas de show, franquias da Benetton, do Boticário etc.

Diversas famílias - cerca de $95 \%$ - que ali viviam foram tragicamente expulsas de suas casas (e juntamente com elas a cultura que construiu e deu 
identidade ao espaço), ocupando hoje ruas, favelas e lugares marginais, à espreita do olhar do turista e dos sobrados reformados (antigas casas) de estética mais imponente, mas também mais amorfa, porque despida de seus verdadeiros atores históricos. A maior parte hoje vive no entorno do Centro Histórico, na comprida Baixa dos Sapateiros, como população de rua, ainda vinculadas ao território do Pelô, onde esbarram-se constantemente com forças policiais que os impedem de transitar por ali.

Após nove anos do início da sua execução, dividido em várias etapas, o Projeto de Reforma e Recuperação do Centro Histórico manteve os seus contornos iniciais, tendo por norte exclusivo a atração de grandes empreeendimentos voltados para a indústria do turismo em detrimento da preservação do elemento humano. Cada vez é mais privilegiada a destinação comercial que transforma, dia-a-dia, o Centro Histórico em um grande palco, onde os "nativos da terra são exibidos em shows ou transitando pelas ruas", subsidiados pelo governo e fantasiados ao gosto do turista, exóticos e pitorescos, sempre disponíveis para fotos de lembranças de uma cultura vilipendiada na sua autenticidade e na sua espontaneidade.

\subsection{7 $7^{a}$ ETAPA DO PROJETO DE REVITALIZAÇÃO: A DESAPROPRIAÇÃO PARA MORADIA}

A noção de patrimônio foi adquirindo diferentes significados ao longo da história; nas ultimas décadas seu conceito passou por uma abertura com o impacto propiciado pela passagem da noção de patrimônio histórico para patrimônio cultural. Segundo Pellegrino (2002), "nessa nova concepção de patrimônio há a inclusão do cultural e das dimensões testemunhais do cotidiano e os feitos intangíveis", em que as obras arquitetônicas deixam de ser vistas como objetos isolados e tornam-se relevantes os conjuntos urbanos e territoriais e também a contextualização tanto física como social e cultural destes. Hoje, entende-se que patrimônio cultural "não se refere apenas a monumentos que representam os melhores momentos de um povo. Ele abrange tudo aquilo que permita compreender o homem e a sua cultura" (Graeff Apud Adin, 2003). 
Em compasso com essas novas concepções de revitalização, o Governo do Estado da Bahia reconhece o erro das etapas anteriores ${ }^{2}$, e adotando o discurso da auto-sustentabilidade e do incentivo à permanência e expressão dos grupos culturais locais, consegue a inserção da $7^{\text {a }}$ Etapa de Reforma do Pelourinho no Programa Monumenta e financiamento do Banco Interamericano de Desenvolvimento no valor de 29 milhões de dólares.

Abrangendo áreas degradadas onde habitam ainda cerca de 1000 famílias, a atual etapa, iniciada em 2000, diferenciou-se no seu discurso oficial por firmar no Projeto de Intervenção, consignado na Pesquisa Sócio-Econômica e Ambiental realizada pela Companhia de Desenvolvimento Urbano do Estado, uma primorosa ênfase no social e no elemento humano que dá identidade cultural ao Pelourinho, ressaltando a importância da permanência da população que atualmente reside no local como forma de preservação do patrimônio cultural.

Uma vez garantido o financiamento, a história se repete. O Governo promulga a lei estadual 8212/02, desapropriando todos os imóveis constantes na área da $7^{a}$ etapa com a finalidade de implementar programa habitacional voltado para população de baixa renda. Nesse programa, entretanto, a moradia seria destinada a servidores públicos. Aqui, muito mais que antes, fica escancarado o intento de "assepsia social do estado": os moradores atuais, portadores da identidade cultural do lugar, deveriam deixar seus imóveis e serem substituídos por outro perfil populacional.

A abordagem sobre os moradores continua igual à das etapas anteriores: oferecimento de uma casa no subúrbio ferroviários de Coutos (completamente distante do Centro e sem a mínima infra-estrutura urbana), ou auxílio-relocação.

Sofrendo pressões e aviltamentos diários para abandonar seus lares, o grupo de moradores do Centro Histórico começa a se organizar criando a Associação de Moradores e Amigos o Centro Histórico - Amach - e leva a questão ao Ministério Público. A partir daí começa a ser debatido pelas instituições, inclusive

\footnotetext{
${ }^{2}$ Pesquisa sócio-econômica e ambiental da $7^{\mathrm{a}}$ etapa do Projeto de recuperação do Centro Histórioco de Salvador, Conder, 2000, pág. 7 : “De um modo geral, os resultados dos planos e projetos não foram os esperados, quando a dimensão urbana não foi adequadamente considerada e a questão cultural enfocada principalmente no turismo.Como conseqüência, a partir de 1991 o Governo do Estado, através de seus órgãos, principalmente o Ipac e à Conder, assumiu a realização de um conjunto de obras e serviços no Centro histórico de Salvador, ampliando as intervenções com a etapa que ora é analisada. ...A gestão da área pelo Estado dirigiu as ações para fins previamente definidos, e como não houve fixação da população no local, este fato interferiu
} 
pelo judiciário, o alcance constitucional da proteção ao patrimônio cultural material e imaterial. Sub-judice, questionada em uma Ação Civil Pública que pleiteia a permanência dos atuais moradores e numa Adin que questiona a validade da lei 8212/ 02, as verbas para a $7^{a}$ etapa são suspensas pelo Ministério da Cultura, responsável pelo repasse, até definição da questão.

$\mathrm{Na}$ querela jurídica, adotada como estratégia de atuação sem nunca abandonar a mobilização pública e a ocupação da mídia, testemunha-se por meio dos documentos de defesa apresentados pelo Estado da Bahia, posicionamentos ideológicos racistas e vis sobre o conceito de cultura:

Conforme a pesquisa sócio-econômica realizada, revelaram-se condições indignas de vida para os moradores do local, não sendo admissível, à ótica constitucional, falar-se em cultura nascida exclusivamente das condições de pobreza e carência que os caracterizam e, muito menos, em requerer proteção para essa cultura, certamente não desejável para uma sociedade que respeite a dignidade de seus integrantes (Declaração do Governador Paulo Souto, ADIN, 2003)

Existem na área - $7^{\mathfrak{a}}$ etapa - expressões típicas urbanas específicas que merecessem o reconhecimento como cultura e, portanto, significassem manifestação da dimensão humana do grupo social ali habitante? Com a devida vênia, não se consegue visualiza-la. Qual a diferença do modo de vida dos habitantes de tão degradada área com outros de áreas igualmente pobres? A vida em cortiços, localizados em imóveis de precária situação, o trabalho informal, a música,a dança, a capoeira ali produzidas se diferem daquelas existentes na Liberdade, Água de Meninos, outros bairros pobres e periféricos de Salvador?

O que sobra mais uma vez, com o devido respeito, é uma "cultura", em verdade um modo de viver produzido pelas condições de pobreza, de dominação sócio-econômica, de exclusão. É esta a cultura protegida constitucionalmente como resultado da dignidade da pessoa humana? Será que não existem necessidades básicas primordiais outras para se garantir a expressão de humanidade, tais como habitação digna, trabalho, educação e saúde?

Os moradores não se vestem de forma típica, de baianas ou pais de santo. Vestem-se com roupas que conseguem, a maior parte de "andrajos". Tampouco área. 
criaram dialeto, mas falam simplesmente errado, arremedo de uma língua que desconhecem.

Recusa-se o Estado da Bahia a reconhecer no "modus vivendi" dos moradores da $7^{\text {a }}$ etapa do Centro Histórico de Salvador cultura popular típica. Existe tão somente um estilo de vida determinado pela pobreza, indigno de ser considerado como expressão da dignidade da pessoa humana. Ressalta-se que a pesquisa sócio-econômica apenas denota pobreza e marginalidade, esta a verdadeira exclusão social. Não há na hipótese cultura popular a ser protegida. (Estado da Bahia, contestação, Adin, 2003)

No caso em tela não há evidência do mencionado acervo patrimonial cultural dos moradores que autorize a concessão da liminar, não tendo o requerente trazido aos autos qualquer elemento que caracteriza a forma de vida dos habitantes do local como parte de seu acervo cultural, a ensejar a sustação provisória da lei 8218/02 ( Tribunal de Justiça, Adin, 2003)

É de ver-se, pois, que para o Parquet enquadra no seu conceito de formador do patrimônio artístico e cultural toda a população da $7^{\mathfrak{a}}$ etapa, embora não demonstre na vestibular qual a contribuição cultural e artística que estudante, biscateiro, empregado doméstico, comerciário, ambulante,encanador, marceneiros, vigilante dão para formação de uma identidade cultural (Companhia de Desenvolvimento Urbano do Estado da Bahia, Ação Civil Pública, 2003)

As declarações acima deixam explícito não só a faceta fascista do Estado da Bahia, como demonstram a compreensão limitada e estreita que têm os membros do judiciário sobre proteção cultural . A decisão que se refere à ausência de elementos nos autos que prove a forma de vida dos habitantes como parte de seu acervo cultural é no mínimo curiosa. A depender da concepção, a expressão forma devida cultural torna-se quase tautológica. Provar a existência de uma cultura onde existem famílias que habitam, trabalham, convivem, constróem, relacionam-se, inventam e reinventam práticas de sobrevivência é considerar o conceito como apartado da prática social. Como afirma Ziegler (1996), a cultura reúne o sentido da experiência e dá sentido à experiência. São as relações simples, espontâneas, traçadas sem maiores expressionismos, por atores anônimos, que, no acúmulo dia-a-dia vão configurando elementos de referência a uma comunidade, a um lugar, e que, internalizados e compartilhados por diferentes gerações, tendem a se fortalecer no percurso da história. 
A luta dos moradores da $7^{\underline{a}}$ etapa já dura cerca de cinco anos. Com a suspensão das verbas pelo Ministério da Cultura, iniciou-se em 2004 um processo de negociação entre o Governo estadual, federal, Ministério Público e Associação de Moradores (Amach), sendo assinado em junho de 2005 um Termo de Ajustamento de Conduta entre o Estado e o Ministério Público garantindo a inserção dos atuais moradores no Programa Habitacional. Para firmar esse processo como um marco diferencial na revitalização do Pelourinho, aguarda-se sua efetiva sua implementação.

\section{O CASO DOS ALFAIATES}

Reflexo retardatário das outras intervenções estatais, a desapropriação do Prédio n 01 da Rua da Misericórdia não se conduziu da mesma forma que a das etapas anteriores. Não por uma redefinição de postura política do Estado ou das suas opções por instrumentos de intervenção mais harmônicos com a vida societária; deveu-se, antes de tudo, à resistência de um grupo de alfaiates e moradores que habitavam o local.

A desapropriação do imóvel, conhecido como "Prédio dos Alfaiates", teve início com o decreto n. ${ }^{\circ}$ 7722, de 20/12/99, do governo do Estado da Bahia, que o declarou de utilidade pública para fins de incorporação ao Projeto de Reforma e Recuperação do Centro Histórico de Salvador.

Em 17 de fevereiro de 2000, a referida empresa ingressou com ação de desapropriação contra o Sr. Antônio da Costa e Silva, pessoa que há aproximadamente quarenta anos encontra-se desaparecida, embora ainda figure como proprietário do imóvel. Na oportunidade, alegando existirem no prédio apenas "eventuais ocupantes" e ressaltando o perigo de desabamento pelo avançado estado de deteriorização do imóvel, a Bahiatursa, por ordem judicial, ganhou imissão na posse do mesmo .

Observa-se que os "eventuais ocupantes" eram os alfaiates, comerciantes e moradores que vinham habitando - alguns desde 1962 - mansa, pacífica e ininterruptamente o "Prédio dos Alfaiates" e que, surpreendidos com a ordem de retirada em menos de três dias, comunicada pelo oficial de justiça, foram considerados "pessoas estranhas ao processo". 
Trabalhando em diversas vias para a garantia dos seus direitos, os alfaiates e moradores procuraram os órgãos públicos responsáveis pela fiscalização e preservação do patrimônio histórico, artístico e cultural como o Iphan e Ipac, recebendo destes apenas a injustificada informação da impossibilidade de agir, em face da eterna falta de condições, dotação de verbas, etc. Procuraram a Defensoria Pública, mas também não tiveram êxito.

Diante da inércia dos órgãos administrativos, foi então oferecida uma representação à Promotoria do Meio Ambiente do Ministério Público Estadual, denunciando as irregularidades cometidas até então no processo judicial e o descaso do Poder Público com a recuperação e preservação do patrimônio artístico, histórico e cultural presente no "Prédio dos Alfaiates", em especial com os próprios alfaiates como elementos tradicionais do local. Requereu-se, na oportunidade, a reforma imediata do prédio e a relocação provisória de todos os seus ocupantes; o acompanhamento do processo de desapropriação em curso; e, no sentido de preservar a integridade da história do imóvel, que o mesmo fosse destinado aos alfaiates após a reforma e desapropriação.

O que se procurou através da representação foi deslocar a discussão para aspectos mais amplos do que então vinham sendo discutidos no processo de desapropriação, em especial o que se entendia como "utilidade pública" na preservação do patrimônio histórico e a incoerência ou contra-senso em extirpar desta o valor do elemento humano.

Lembrou-se, na oportunidade, que qualquer medida de proteção que fosse adotada em relação ao "Prédio dos Alfaiates", por qualquer entidade da Federação, seja desapropriação, reforma ou restauração, não poderia abdicar da preservação da integridade e da dignidade humana. Os alfaiates, famosos artesãos que conferiam elegância e movimento ao local, nomearam o prédio pelo exercício de sua profissão nos tempos áureos da Rua da Misericórdia. Foram décadas de intenso labor, mas também de reconhecimento e respeito, erigidas entre as então firmes paredes do Casarão Amarelo.

A própria referência que o prédio alcançou junto à sociedade - "Prédio dos Alfaiates" - impôs-se ao imaginário coletivo sobre o valor social do trabalho, não do trabalho que alimenta o voraz capital, o da linha de produção, o da alta exploração, mas daquele que integra os homens, na sua vida em comunidade. 
Afinal de que vale um patrimônio da humanidade quando ele mesmo não funciona como um patrimônio local, municipal e regional. Nas palavras de Ana Fani Alessandra Carlos

o espaço produzido pela industria do turismo perde o show perde o sentido, é o presente sem espessura, quer dizer, sem história sem identidade, neste sentido, é o espaço do vazio. Ausência. Não-lugares(...)Isto porque o lugar é, em sua essência, produção humana, visto que se reproduz na relação entre espaço e sociedade, o que significa criação, o estabelecimento, entre comunidade e lugar, identidade essa e que se dá por meio de formas de apropriação para vida. ${ }^{3}$

Orientado, entre outros, por estes fundamentos, o Ministério Público, diante da provocação dos alfaiates e moradores do prédio, abriu inquérito civil público, realizando audiências públicas a fim de apurar, junto ao Estado, a sua concepção de patrimônio histórico e a destinação que seria dada ao imóvel.

Em paralelo ao processo judicial e diante da resistência de submissão à equivocada ordem judicial, foi aberto um canal de negociação direta entre as partes. O "caso dos alfaiates" passou a ter a cobertura da imprensa local, ganhando repercussão e causando grande comoção e indignação na comunidade soteropolitana. Foram realizados atos públicos, manifestos de apoio de professores universitários, associações de funcionários etc. Diante do descalabro verificado nas outras desapropriações, mas agora concretamente publicizado com o "Caso dos Alfaiates", revelou-se a fragilidade da motivação do ato de desapropriação que não se sustentaria sob o fundamento da preservação histórica sem relevar a preservação dos agentes históricos vivos no local.

Por fim, através de acordo realizado na terceira audiência pública, reconheceu-se o direito de retorno dos alfaiates ao "Prédio dos Alfaiates" como único meio de manter a integridade histórica do imóvel, bem como garantiu-se o pagamento de indenizações - agora baseadas em justos critérios - pelo ato da desapropriação em si.

A experiência do grupo liderado pelos alfaiates firmou, por si e envolvendo a comunidade, uma nova página na história, afirmando um conceito de desenvolvimento urbano sustentável que não considere apenas o valor artístico das

\footnotetext{
${ }^{3}$ In Turismo, espaço e cultura, Ed HUCITEC,São Paulo, 1999
} 
edificações, pois este é notório; mas que valorize o homem enquanto criador de um espaço simbólico que não sobrevive com a sua ausência.

\section{CONCLUSÃO}

Relegando a adoção de medidas mais contínuas, compartilhadas e participativas na preservação do Pelourinho, os atos desapropriatórios em massa ( desapropriação "por quarteirões") adotados pelo Governo do Estado da Bahia a partir da década de 90 serviram ao caráter genocida, fascista e segregador do Projeto de Reforma e Recuperação do Centro Histórico de Salvador, cujo único fim foi a inserção do capital de consumo, sobretudo estrangeiro, no local, e a exclusão das "memórias indesejáveis", esculpidas, em sua maioria, por pobres e negros. Um projeto que deformou e destruiu toda a essência histórica da comunidade do Pelourinho, erigindo lojas e restaurantes sobre o esfacelamento de vidas humanas e de tradições culturais.

À luz dos princípios constitucionais, administrativos e ambientais que ordenam a preservação dos sítios históricos em consonância com a dinâmica do local, que determinam a permanência e defesa dos grupos culturais, primando pelos valores sociais do trabalho e da moradia, e a mais recente promulgação da Lei do Patrimônio Imaterial, verifica-se que a desapropriação no Centro Histórico de Salvador distanciou-se em muito de uma plena proteção do patrimônio histórico, artístico e cultural ali presente. E foi preciso muita resistência e luta para a afirmação de memórias como a dos Alfaiates e das poucas mais de 1000 famílias que conseguiram chegar até a $7^{\text {a }}$ Etapa.

Contrapondo-se à apropriação pelo Poder Público, propomos a revaloração da propriedade particular no Pelourinho como garantia da liberdade de expressão dos seus habitantes, de preservação da sua heterogeneidade cultural e de polifuncionalização dos espaços arquitetônicos. Sobrelevando-se o conceito de "interesse público" na preservação da história, os aspectos estáticos dos monumentos arquitetônicos devem comportar o dinamismo dos atores sociais que orientam a função dos espaços na contemporaneidade.

Tomando por base essa relação entre público e privado, macropolítica e micropolítica, agregadas num conceito de transformação e libertação social que 
podem se desenvolver e se potencializar nas esferas das particularidades e microracionalidades, o regramento excessivo do Estado sobre o Pelourinho possibilitado através da drástica medida de apropriação pública dos bens tombados - acabou por minimizar as plúrimas formas de pulsação cultural que dão significado ao patrimônio histórico-artístico-cultural.

No que tange às políticas patrimoniais, conclui-se pela inviabilidade de uma macropolítica - expressa na idéia de "projeto" e engrenada pela desapropriação em massa, e pela necessidade do exercício de micropolíticas permanentes, definidas em conjunto com os interesses específicos daqueles que imprimem identidade e singularidade em cada imóvel tombado. A afirmação de uma política de preservação conciliatória, baseada no domínio privado dos imóveis tombados por suas gentes e no controle e fiscalização sobre o cuidado com as estruturas físicas por parte do Estado, centra-se no fato de serem os homens e seus fazeres os propulsores, por excelência, da história. 


\section{REFERÊNCIAS BIBLIOGRÁFICAS}

CEAS. Como Salvador se faz: Dossiê das Lutas das Comunidades Populares de Salvador. Salvador, 2003.

Companhia de Desenvolvimento do Estado da Bahia - Conder. Pesquisa sócio Econômica e Ambiental da 7aㅡ Etapa do Projeto de Recuperação do Centro Histórico de Salvador (BA). Projeto Monuumenta/BID. VOLUME 1, Salvador, 2000.

CHOAY, Françoise. A Alegoria do Patrimônio. Tradução: Luciano Vieira Machado. São Paulo: Estação Liberdade: Editora UNESP, 2001.

Governo do Estado da Bahia (GEB). Procuradoria Geral do Estado (PGE). Procuradoria Especializada Judicial. Contestação da Ação Direta de Inconstitucionalidade no 38.148-7/2002. Salvador, 10.04.2003.

MEMORIAL. Resistência dos Alfaiates Contra a Ação do Estado no Processo de Desapropriação do Prédio dos Alfaiates. Salvador, 2001.

Partido dos Trabalhadores (PT). Ação Direta de Inconstitucionalidade com Pedido de Medida Cautelar (ADIN no 38.148-7/2002). Salvador, 2002.

PELLEGRINO, Carlos Tranquilli. Patrimônio Cultural Urbano: de quem? Para o quê?. 2002

ROCHA, Carlos Demócrito Monteiro da. Pelourinho: Simulacros e Morte Social. Monografia apresentada ao Curso de Pós-Graduação Potenciais da Imagem da Universidade Federal da Bahia. Salvador, 2002.

SILVA, José Afonso da. Ordenação Constitucional da Cultura. São Paulo: Malheiros Editores, 2001.

URIARTE, Urpi Montoya. Intervenções Recentes em Centros Históricos: as práticas de "recuperação" dos centros históricos de Salvador, Lima e Quito. São Paulo: Centro Virtual de Estudos Históricos (Ceveh), 1999. [ceveh.com.br]

ZIEGLER, Jean. A vitória dos Vencidos. Opressão e Resistência Cultural. forense Universitária, 1996. 